\title{
Os homens não vêm! Ausência e/ou invisibilidade masculina na atenção primária
}

\author{
Men don't come! Absence and/or invisibility \\ in primary healthcare services
}

\author{
Romeu Gomes ${ }^{1}$ \\ $M$ artha Cristina Nunes M oreira ${ }^{1}$ \\ Elaine Ferreira do $\mathrm{N}$ ascimento ${ }^{1}$ \\ Lucia Emília Figueiredo de Sousa Rebello ${ }^{1}$ \\ Márcia Thereza Couto ${ }^{2}$ \\ Lilia Blima Schraiber ${ }^{3}$
}

${ }^{1}$ Fundação Oswaldo Cruz, Instituto Fernandes

Figueira, Departamento de Ensino. Av. Rui Barbosa

716/40 andar, Flamengo.

20550-011 Rio de Janeiro

RJ.romeu@iff.fiocruz.br

${ }^{2}$ Universidade de São

Paulo.

${ }^{3}$ Departamento de M edicina

Preventiva, Faculdade de

M edicina, U niversidade de

São Paulo.
Abstract This article deals with the masculine absence and/or invisibility in primary healthcare services and the consequent exclusion of men of the preventive care. The analytical frame is based on the literature that discusses care related to health and masculinity. M ethodologically the study uses qualitative analysis of the empirical data (reports) gathered by semi-structured individual interviews of 20 professionals and by two focus groups with 12 workers of the nursing assistants staff of two primary healthcare services of the city of Rio de Janeiro (RJ). Results point out two significant dimensions: the structural and the symbolic one. The structural dimension re veals low investment in the services' organization related to gender perspective approach, reinforcing the common sense that men are not primary healthcare users. The symbolic dimension shows the non consideration of the masculine universe themes as the difficulty men have in revealing themselves to the professional, demanding a special privacy for attendance. Dealing with these questions enhance the possibility of changing practices that are making men invisible to the primary healthcareprograms and taking them apart of the self care condition as well as the condition of carriers of others.

Key words M en, Primary health care, Absence, Invisibility
Resumo 0 artigo se debruça na discussão da ausência e/ou invisibilidade masculina nos serviços de atenção primária, com consequente ausência da inclusão dos homens nos cuidados preventivos. A grade analítica está fundamentada na literatura que discute cuidados em saúde e masculinidade. 0 método deste estudo se baseia em uma análise qualitativa do material empírico advindo dos depoimentos, na forma de entrevistas individuais semi-estruturadas, de vinte profissionais, e do material de dois grupos focais com doze trabaIhadoras de nível médio de enfermagem de dois serviços de saúde em atenção primária do município do Rio de aneiro (RJ). Os dados da pesquisa apontam para duas dimensões dignas de atenção: a estrutural ea simbólica. A estrutural revela pouco investimento na organização do serviço numa perspectiva de gênero, reforçando o senso comum de que os homens não são usuários da atenção primária. A simbólica diz respeito à não consideração de temas do universo masculino, como a dificuldade que homens têm em se desnudar para o profissional, demandando uma privacidade no atendimento. Trabalhar nessas questões pode possibilitar a transformação das práticas que tornam os homens invisíveis nos programas de saúdedeatenção primária, afastando-os da condição de cuidadores de si e dos outros.

Palavras-chave Homens, Serviços de saúde, Ausência, Invisibilidade 


\section{Introdução}

Este artigo ancora-se na discussão sobre saúde e masculinidade ${ }^{1-4}$. Os modelos de masculinidade e a maneira como se dá a socialização masculina podem fragilizar ou mesmo afastar os homens das preocupações com o autocuidado e a busca dos serviços de saúde ${ }^{5-9}$.

A perspectiva do cuidado masculino podeseguir um caminho positivo quando incorpora a ideia de que ao homem também é permitida uma atenção consigo próprio. Por outro lado, esse cuidado também pode distanciá-lo da saúde em geral quando atinge o limite do culto extremado ao corpo $^{10,11}$. Alguns homens, quando promovem 0 cuidado de seu corpo, cultivam um extremo fisiculturismo e, nesse aspecto, o cuidado desi pode transformar-se em risco de adoecimento.

A reivindicação deuma política desaúdemais integral voltada para a população masculina poderia, à primeira vista, ser tomada como uma oposição aos programas de gênero destinados à saúde da mulher ${ }^{12}$. No entanto, éa partir da própria dimensão degênero queseadvoga uma abordagem também do masculino, uma vez quetanto homens quanto mulheres necessitam ser vistos em sua singularidade e em sua diversidade no âmbito das relações sociais mais amplas que estabelecem ${ }^{10}$.

O conhecimento das singularidades pode possibilitar uma melhor aproximação da forma imediatamente relacional do par masculino-feminino, assegurando uma maior densidade de conhecimento das especificidades de cada pólo em interação, possibilitando ganhos tanto para a saúde masculina, como para a discussão de temas da saúde feminina que só avançam na medida em que se consegue a participação masculina em seu enfretamento ${ }^{12}$.

Dessa forma, se faz importante problematizar se a "não presença" dos homens nos serviços de saúde está associada a uma suposta ausência ou a um não reconhecimento da sua singularidade, que pode ser interpretada como uma invisibilidade não do sujeito/usuário e sim das políticas de saúde em reconhecê-lo e, portanto, incorporá-lo também como um protagonista de suas ações. Corrobora essa necessidade o fato de a atenção primária em saúde, no Brasil, ser vista como a assistência provida pela rede horizontalizada de serviços de saúde pública - os centros de saúde ou unidades básicas e voltados historicamente para os cuidados maternos einfantis $5^{13,14}$. Tais unidades são criadas no modelo da educação sanitária que sucede ao campanhismo na saúde pública brasileira ${ }^{15}$ e se relacionam às próprias origens de uma medicina preventiva no interior da assistência à saúde, com as ações de higiene da mãe no pré natal e da criança na pue ricultura. Com isso, embora em tese destinada a toda a população, a aten ção primária se identificou num momento e num espaço assistenciais feminilizados, com o predomínio de uma cultura profissional também ligada a esses segmentos populacionais 9 .

Nesse sentido, a proposta do artigo se debruça na discussão da ausência e/ou invisibilidade masculina nos serviços de atenção primária, com consequente ausência da inclusão dos homens nos cuidados preventivos, a partir da interpretação de profissionais de saúde de dois serviços específicos da cidade do Rio de Janeiro.

\section{M étodo}

Este estudo - de natureza qualitativa - integra uma pesquisa mais ampla, cujo objetivo foi analisar como se dá a relação homens-assistência à saúde em quatro estados (Rio Grande do N orte, Pernambuco, Rio de Janeiro e São Paulo), financiada pelo Conselho N acional de Desenvolvimento Científico e Tecnológico (CN Pq). Aqui, focalizamos os depoimentos de profissionais de saúde de atenção primária de dois serviços do município do Rio de Janeiro (RJ), denominados neste trabalho de Serviço I e Serviço II. Os serviços foram escolhidos a partir dos critérios de se selecionar um serviço com atividades especificamente voltadas para homens e um serviço sem essa especificidade. Para essa escolha, solicitou-se indicação da Secretaria de Saúde do Município do Rio de Janeiro (RJ). Com base nessa indicação, definiram-se dois serviços de uma mesma área programática (5.2 - Zona O este).

No que tange aos sujeitos deste estudo, foram realizadas vinte entrevistas semi-estruturadas, envolvendo gerentes e coordenadores de programas nas unidades e profissionais da assistência, e dois grupos focais (GF) com auxiliares de enfermagem, envolvendo doze profissionais ao todo. 0 uso do GF sejustifica na medida em que se buscou captar a opinião do conjunto dos profissionais desse segmento.

No recorte temático por núcleos de sentido, em termos deorganização dos depoimentos, considerou-se o sexo e a formação profissional de base de cada entrevistado, o que permitiu situar o discurso no interior de sua posição em um habitus ${ }^{16}$ profissional. De acordo com Bour- 
dieu ${ }^{16}$, o habitus é um princípio universal de visão e divisão, como um sistema de categorias de percepção, de pensamento e de ação. Essa perspectiva - essencialmente relacional - contribui para situar os atores no interior de um campo, no caso profissional e de gênero. Assim, foram envolvidas diversas categorias profissionais, pre valecendo a maioria feminina (Q uadro 1 ). Cabe ressaltar que a categoria gestão não foi especificada propositadamente, buscando evitar a duplicidade deinformação. A função degestor, neste caso, éexercida por um médico eum engenheiro.

Antes da realização do trabalho de campo, foi obtida a aprovação do Comitê de Ética em Pesquisa da Secretaria M unicipal de Saúde do Rio de Janeiro. Para garantir o anonimato na pesquisa, foram criados nomes fictícios para os profissionais entrevistados, iniciados pela letra $P$, seguidos dos códigos alfanuméricos: 1RJ (Serviço I) e2RJ (Serviço II).

No tratamento dos depoimentos, utilizou-se o método de interpretação de sentidos, baseando-seem princípios hermenêutico-dialéticosque interpretam o contexto, as razões e as lógicas de falas, ações e inter-relações entre grupos e instituições ${ }^{17,18}$. Partiu-se da leitura compreensiva do material; passamos pela problematização das ideias presentes nos depoimentos e pela busca de significados socioculturais (subjacentes às falas dos sujeitos) e, por último, estabeleceu-se um diálogo entre ideias problematizadas, informações provenientes de outros estudos acerca do assunto e o referencial teórico do estudo.

A partir da análise e da interpretação dos dados, foram reunidos os sentidos subjacentes aos depoimentos dos profissionais em três eixos de discussão: organização dos serviços para atender os usuários, qualificação dos profissionais para 0 atendimento das demandas masculinas, bem como os sentidos atribuídos ao ser usuário homem.

\section{A organização dos serviços}

Subjacentes aos depoimentos dos profissionais, há sentidos atribuídos à organização dos serviços que, de certa forma, dificultam um atendimento julgado adequado por eles. Parte de seus depoimentos não diz respeito apenas ao atendimento aos homens, mas também às mulheres. Revelam, de um lado, problemas de acesso de segmentos populacionais aos serviços públicos de saúde e, de outro, limites que esses serviços têm em dar conta de suas demandas de atendimento. Os depoimentos que seguem ilustram tais limites: "A porta de entrada da saúde pública é muito ruim. Nossa agenda está lotada." (Paloma, assistente social, 1RJ)

"Vagas limitadas pra determinados tipos de coisas, média ou alta complexidade, que a gente não consegue resolver em nível local. Então, você depende de outras organizações." (Pepita, fisioterapeuta, 1RJ)

As dificuldades com o funcionamento em rede, pouco resolutiva, formando filas de espera, contribuem para a evasão dos usuários do sistema. A demanda cresce, mas o número de profissionais não, gerando uma sobrecarga nas unidades, onde determinados especialistas são encontrados.

É interessante destacar que a preocupação com a porta de entrada nem sempre está voltada para a qualificação, ou acolhimento ao usuário, mas para garantir um controle da clientela, visando à segurança do profissional, em realidades de comunidades onde a violência é uma forma de expressão de linguagem: "M elhor controle de porta de entrada. Aqui é lugar violento e as pessoas toda hora te intimidam ou até partem pra agressão, isso é real. 0 profissional fica com medo, tivemos médicas sendo juradas de morte." (Pompeu, médico, 2RJ)

Devido ao fato de, em geral, as práticas serem moldadas a partir da estrutura objetiva do sistema de saúde, a compreensão da organização dos serviços éinfluenciada por aspectos relacionados ao campo formalístico, organicamente relacionados aos modos de gestão da política, de

Quadro 1. Categorias dos profissionais entrevistados segundo sexo.

\begin{tabular}{|c|c|c|c|c|c|c|c|c|}
\hline \multirow{2}{*}{ Sexo } & \multicolumn{7}{|c|}{ Categoria } \\
\cline { 2 - 9 } & Medicina & $\begin{array}{c}\text { Serviço } \\
\text { Social }\end{array}$ & Enfermagem & Psicologia & Odontologia & N utrição & Fisioterapia & Engenharia \\
\hline Feminino & 2 & 2 & 7 & 2 & 1 & 1 & 1 & - \\
\hline Masculino & 1 & - & 1 & - & 1 & - & - & 1 \\
\hline
\end{tabular}


ausência de segurança, da infra-estrutura material (horários, remuneração, inputs para propiciar a formação/trabalho interdisciplinar e contínuo aprimoramento dos profissionais). A dimensão espacial da cidade do Rio de Janeiro também se configurou como aspecto relevante, pois dependendo de onde se localizam os serviços, os profissionais enfrentam maisfortementeas questões deviolência.

Os profissionais entrevistados destacam que a organização do sistema de saúdehistoricamente vem sendo desenhada a partir da valorização do cuidado à saúde da mulher e da criança, tanto no meio profissional quanto no imaginário social e, por conta disso, demarca as diferenças de abordagens de acolhimento por gênero, promovidas pelos serviços de saúde (instância micro) e as políticas de saúde (instância macro): "[Há desigualdades] porque os programas de saúde são mais voltados para a mulher, criança e adolescente. E 0 sexo masculino, o homem, o jovem adulto, já não existe tanta preocupação." (Paulete, assistente social, 2RJ)

A pouca procura masculina também aparece associada à ausência de acolhimento ou 0 acolhimento pouco atrativo, que pode estar relacionado à frágil qualificação profissional para lidar com o segmento masculino. Nesse raciocínio, seria necessária a adoção de estratégias que se voltassem tanto para a ampliação da oferta de ações como para a sensibilização dos homens para cuidarem de sua saúde. Assim, uma estratégia possível de ser adotada seria a qualificação da porta da entrada, voltada para 0 acolhimento e a resolutividade, desdobrando-se na construção de uma rededeatenção à saúde eficaz: "[ $N$ ão há] para esse homem uma porta deentrada qualificada, com acoIhimento." (Paulina, enfermeira, 1RJ)

"Falta de conscientização de que há uma necessidade de atrair esses homens e que [esse] homem também adoece." (Plínio, enfermeiro, 1RJ)

[No caso dos homens] tenho pouca oferta de serviços, em relação à demanda, nós temos pouquíssimos urologistas, que seria também importante profissional." (Pedro, médico, 1RJ)

A crítica se amplia quando o foco é a inexistência de programas voltados para a saúde masculina, convivendo com a ideia de que a atenção primária não oferece profissionais que componham a assistência à saúde do homem, principalmente urologistas. No entanto, ainda que se reivindique determinada especialidade, com a justificativa de que o generalista não dá conta de atender a especificidade do homem, faz-senecessário evitar uma visão reducionista ou fragmen- talizadora da atenção primária, em que circunscreve a especificidade do usuário homem apenas na urologia.

De um lado, observa-se o fato de que as unidades básicas de atenção primária foram organizadas para o funcionamento em horários quase sempre incompatíveis com o "homem trabaIhador", acoplado ao reconhecimento no mundo do trabalho de que apenas a mulher teria ne cessidades de uso regular dos serviços. Por outro lado, constata-se que o estigma que reúne homem jovem/risco/marginalidade é desafio para o acolhimento dos homens por meio da ampliação dos horários de funcionamento do serviço: "[Seria importante] um turno específico para adulto. A segurança ébem complicada. Aqui essa área é meio perigosa." (Perilo, dentista, 2RJ)

Ainda em relação à estrutura física dos serviços, essa não propicia o estabelecimento de um atendimento com maior privacidade, como apontam os trechos que se seguem: "Aqui a gentedividea sala etem certas coisas atéque, para o menino, ele fica meio constrangido, mas isso seria para a menina também." (Perla, nutricionista, 3RJ)

"Não acho certo ter uma clínica de homem e uma clínica de mulher, mas tem horas também queo homem precisa ter a sua privacidade." (Pilar, dentista, 2RJ)

Essas falas podem ser associadas a um padrão liberal de construção profissional, em quea consistência e a força profissionais residem no segredo e na invisibilidade da prática, daí a privacidadeestar relacionada ao segredo, como uma necessidade do profissional. Podem também se associar à ideia de que os temas que surgem em uma consulta com usuários homens transbordam para o campo da sexualidade, das dúvidas que só podem ser compartilhadas em um espaço privado, onde o segredo é garantido.

A qualificação dosprofissionais frente às demandas da saúde do homem

Nesteeixo desentidos, uma primeira posição está associada à maneira como o profissional consegue ou não se dedicar ao planejamento de sua prática, contribuindo para a construção de planos de trabalho. Deum modo geral, na ótica dos profissionais, o sistema de saúde tende a responsabilizá-los pelo êxito ou fracasso de sua ação junto aos usuários, considerando-os inaptos a uma escuta qualitativa, sem problematizar que historicamente esse mesmo sistema priorizou o atendimento à mulher e a criança e reprimiu 0 
segmento masculino, mesmo sendo esta creditada à relação profissional/usuário: “A gente mesmo às vezes reprime essa demanda. Se o profissional estivessemais preparado para uma escuta [adequada], a gente poderia estar atendendo mais 0 usuário masculino. Acho que [o profissional] não está preparado para ninguém, mas pior para o sexo masculino." (Paulete, assistente social, 2RJ)

"A mulher é mais responsável pela sua saúde. Já o homem não tem tanta responsabilidade, isso acaba causando um pouco de desânimo nos outros profissionais." (Plínio, enfermeiro, 1RJ)

Um perfil tranquilo, receptivo, flexível eobjetivo de profissional parece ser necessário para lidar com uma imagem de um homem agressivo, impaciente, que não gosta de esperar e que costuma questionar as rotinas profissionaisqueseguem uma rigidez de horários e rotinas burocráticas: "Tem uma burocracia muito burra, que dificulta, emperra e você acaba não tendo mais esse cliente na mão, ele vai embora." (Piedade, psicóloga, 3RJ)

0 produto [do profissional] é baseado não só no seu lado técnico, mas no seu lado humanitário. Quanto mais paciente você for, melhor você de sempenha a sua atividade" (Petrônio, médico, 2RJ)

As qualidades pessoais ficam destacadas na fala dos profissionais que avaliam sua atuação com o usuário masculino. Essas qualidades são referências não só para os usuários, mas também para as equipes, produzindo circuitos de trocas e reciprocidade, na circulação de bens de cura ${ }^{19}$. N esse espaço de trocas, faz sentido o encontro em grupo como um estímulo de sociabilidades: "O que poderia ser melhorado é o encaixe multiprofissional que meajudasse também a lidar com algumas situações." (Plínio, enfermeiro, 1RJ)

"Tinha um grupo de homens que se reuniam. Elesconversavam, tinham palestras. Eu achava isso muito bom. Ficavam aqui até nove, dez horas da noite. Eu acho esse encontro muito bom, afetivo entre eles." (Pilar, dentista, 2RJ)

Destacam-se as ideias de que há uma indisponibilidade de alguns profissionais para o trabalho em equipe em virtude de um desinteresse pelo que seja o público: "Q uando eu cheguei, tentei implantar um projeto multidisciplinar. As pessoas só estão interessadas realmente na liderança, na estatística, número e não avaliam nada disso." (Priscila, enfermeira, 2RJ)

Segundo os profissionais, a construção de uma equipe interdisciplinar exige uma série de habilidades e pactuações, esbarrando nas expectativas de um em relação ao outro, sem desconsiderar a necessidade de provocar as interlocuções internas esuas diferentes especialidades: “Eu acho quea gente tinha que ter uma maior integração com o Serviço Social no sentido de se ter um mecanismo de vale transporte, para que pudesse 0 tratamento não ter estas faltas. U ma coi sa que garantisse a qualidade." (Pâmela, psicóloga, 3RJ)

A ideia de referência ganha destaque no discurso do profissional que desenvolve um trabaIho específico com os homens, revestido da falta de parcerias que transcendam um modelo medicalizante e que caminhem através de avaliações conjuntas e práticas integradas. "Houve uma necessidade da unidade do serviço social pra união profissional atender a esses homens e mesmo não tendo outros profissionais que me ajudem nesse trabalho, não vou desanimar . Acho que, futuramente, consiga modificar um pouco a cabeça de alguns profissionais em relação ao atendimento ao homem." (Plínio, enfermeiro, 1RJ)

Esse cenário aponta que os profissionais em princípio considerados como aqueles que re alizam seu trabalho de maneira pouco reflexiva - estão buscando, ainda que seja num plano ide al, relações profissionais voltadas para a realização do trabalho numa perspectiva mais integrada entre as diversas áreas que compõem as especialidades. Esse posicionamento reflexivo, de acordo com Bourdieu ${ }^{16}$, mobiliza um conjunto de saberes teóricos e metodológicos do campo das disposições exógenas eendógenas, articulando-os concomitantemente ao saber e a vontade de compreender.

\section{O homem \\ como usuário dos serviços de saúde}

Neste eixo de discussão, destacam-se principalmente os sentidos atribuídos pelos profissionais à ausência dos usuários masculinos nos serviços. Esses trazem uma dimensão valorativa de gênero e de geração, ancorada em modelos culturais. A maneira como os profissionais recorrem à cultura, às diferenças de gênero eà geração denota um viés determinista, em que de al guma forma o lugar do agente promotor de mudança fica submetido a um papel secundário frente ao cenário social. As falas remetem a aspectos valorativos, em que os atores entrevistados buscam interpretar os comportamentos masculinos, situando-os em um universo de relações evalores. Por aspectos valorativos entende-se 0 universo da cultura e da subjetividade, da interpretação dos fenômenos e acontecimentos relacionados ao eixo da necessidade e do cuidado de saúde, no marco das diferenças de gênero e geração. 
Segundo os entrevistados, há uma marca cultural, no aprendizado de como se cuidar, que faz com que o homem chegue ao serviço de saúde com intercorrências graves. Há no ambiente familiar uma socialização de ideias que não estimulam um comportamento masculino de autocuidado, já que ao longo da trajetória pessoal o cuidado dos homens é geralmente mediado por figuras femininas como mãe, companheira e filha(s): "O homem não tem essa cultura de se cuidar. Você enquanto mãe também não passa isso para os filhos." (GF 5, 2RJ)

Esse tipo de comportamento influencia não só no estado em que esse usuário chega ao serviço de saúde, mas também na maneira como 0 utiliza. A explicação para esse comportamento se liga às exigências dos modelos hegemônicos de masculinidades: "Preconceito. Não, eu sou forte, eu sou macho, eu não tenho nada, eu tenho que mostrar queeu sou forte" (Penha, enfermeira, 2RJ).

O s entrevistados recorrem às explicações sobre a cultura para tentar dar conta desse comportamento masculino de não cuidar da saúde, associando a isso um reforço por parte da ausência de programas no nível local voltados especificamente para essa população. Esse tipo de comportamento masculino gera uma busca por ações de saúde com a doença instalada: "Isso é uma questão cultural, o homem não tem muito essa preocupação de cuidar da saúde e isso junta com a falta de vontade política que eu digo, porque não existem programas voltados na Secretaria." (Paulete, assistente social, 2RJ)

"H omens que chegam lá com câncer de próstata já na fasefinal. Eles demoram a buscar 0 atendimento, eles só vêm no último caso." (Perpétua, enfermeira, 2RJ)

Há uma exigência, socialmente construída, na ideia de que um homem deve ser forte, desdobrando-se na figura de um homem que teme cuidar de sua saúde, adiando tratamentos preventivos. A doença e suas possíveis associações com a finitude da vida representam um perigo e uma ameaça à vida. É interessante essa associação entre frequência ao serviço desaúdee morte, como se a proximidadecom esse lugar remetesse muito mais ao eixo do tratamento da doença e de suas sequelas, do que a um lugar de cuidado com a vida ea saúde. Tal perspectiva parece estar sintonizada com a representação histórica e socialmente compartilhada deque há uma descontinuidade entre saúde e doença, que esta última interrompe o ciclo vital e não a compõe. Essa perspectiva dificulta a incorporação da experiência de adoecimento e sua elaboração na direção do autocuidado. A doençaéalgo quevem defora, é descoberta, acomete, invade e por isso amedronta, como reforçam os trechos a seguir: "H omem tem muito medo de encarar as coisas, as mulheres são mais corajosas. A tépor medo demorrer. Os idosos procuram. É medo de morrer. Covardia do homem ter que deixar o trabalho. Só vem quando está no limite." (GF 1, 2RJ)

Nos grupos focais, ganha força a associação entre o significado do cuidado à saúde e o medo da morte. Na discussão em grupo, a figura feminina é destacada como aquela que sustenta afetivamente a casa e os cuidados com os filhos e com o próprio homem. Seu papel ganha um qualificativo estruturante na diferença entre os gêneros, 0 homem sustenta materialmente a casa e a muIher, afetivamente. É a mulher a referência de cuidado e nesse contraste o papel feminino é ressaltado. A covardia de buscar um cuidado associado ao medo de ter uma doença e à ideia de que pode vir a contar com a mulher como apoio nas suas dificuldades também ganham peso nos depoimentos: "Eu já acho que eles têm muito medo deencarar a realidadedascoisas, entendeu? Eletem a gente como suporte. Se adoecer, se morrer, tem a gente que cuida. Eu vejo por esse lado: medo e por ter a gente como suporte." (GF1, 2RJ)

Relativizando a perspectiva de que os homens são signatários da fortaleza que lhes é atribuída socialmente, uma das participantes recorre a uma "naturezafeminina forte" quesuperaa do homem, ainda em idades precoces, questionando a leitura social sobre a força masculina e justificando a capacidade de superação não só da dor, como da morte, a partir de uma suposta natureza feminina: “Essa questão de índice de morte eu já observava no neonatal. Nascia uma menina e um menino, era mais fácil o menino morrer do quea menina. Parece que a menina tinha mais força, mais garra para a sobrevivência e os meninos não". (GF1, 2RJ)

Outro aspecto que ganha destaque na fala das entrevistadas e que no contexto do grupo provoca um debate com descontração é a diferença entre homens emulheres na real ização dos exames preventivos. 0 preventivo de câncer de próstata para o homem motiva 0 aparecimento de preconceitos, na forma de chistes e brincadeiras: “U ma questão também é o preconceito: foi levar dedada." (GF, 2RJ)

"M eu pai não queria fazer [o exame de próstata]: 'Poxa, vai. É só o senhor não gostar. Se o senhor gostar é perigoso! E ele faz." (GF, 2RJ)

Gomes ${ }^{10}$ aponta para o papel que a dimensão simbólica ocupa na constituição de imagens acerca da sexualidade masculina. Essa dimensão 
simbólica, socialmentecompartilhada, sefaz presente no discurso e na percepção das mulheres que trabalham com homens, como no caso das participantes dos grupos focais.

No que se refere ainda à demanda pelos exames de preven ção do câncer de próstata, um dos profissionais acessaum repertório explicativo que destaca o pudor masculino relacionado à percepção de invasão do toque retal, como um fator queinterfere na construção de conceitos pejorativos que geram resistência à necessi dade de realizar o exame: "Por eles considerado um exame de conceitos pejorativos, ele fica mais resistente, se ele comentar com os amigos que ele foi fazer um exame de próstata, nego já vai começar com um outro tipo deinterpretação, mesmo na brincadeira." (Pe trônio, médico, 2RJ)

A necessidade de privacidade é apontada como um fator quefavoreceria o comportamento de adesão ao tratamento de saúde por parte dos homens. Esses são percebidos como impacientes e objetivos, e ao mesmo tempo como envergonhados quando na proximidade com as mulhe res em grupos mistos: "Falta um pouco de privacidadenaquela sala [porta de entrada]. Tinha que ter uma sala mais preservada, porque a sala é de marcação e de acolhimento." (GF, IRJ)

Além de assinalarem que para o homem a privacidade da consulta com o profissional é importante, os entrevistados afirmam que a estrutura do serviço de saúde não favorece o reconhecimento do comportamento masculino como pautado na objetividade, na necessidade de ser reconhecido na sua especificidade masculina.

0 fato de o homem ser identificado como alguém mais prático e objetivo tanto significa uma dificuldade, quanto uma facilidade. Na realidade, a objetividade e praticidade masculinas interferem na adesão e na construção de vínculo com o serviço de saúde, na busca de serviços mais rápidos, resolutivos eque demandem menos de suas disponibilidades de horário. Isso pode significar a ligação entre resolver o problema e nunca mais retornar ao serviço. No caso de tratamentos que exigem acompanhamento contínuo, isso é um fator importante que interfere na evasão.

Os dados dos grupos focais apontaram para as possíveis dificuldades dos homens em partiIhar com as usuárias mulheres espaços oferecidos pelos serviços de saúde para as palestras de planejamento familiar, que parecem mobilizar sentimentos de vergonha e inibição. Destacamos que esses grupos foram compostos eminentemente por trabalhadores do gênero feminino: "[No grupo de] planejamento familiar [só há] dois homens. Eles têm vergonha de perguntar por que só tem mulher, e as mulheres ficam com vergonha de perguntar por que só tem dois homens. Eles têm vergonha de vir." (GF, 1RJ)

A identificação dos sentimentos de vergonha e inibição no ambiente de grupo, compartilhados por homens e mulheres, reacende a perspectiva da diferença entre os gêneros e da ideia de que existem assuntos de mulheres e assuntos de homens. E que, para esses assuntos, homens e mulheres organizam-secom seus pares, compartilhando seus segredos. Frente à temática da sexualidade, ressaltam-se os anseios pela privacidade, pelo segredo, pela possibilidade de escoIher quem pode participar da "conversa de homem" e da "conversa de mulher" 20. Os homens são socializados para falar da mulher e não com a mulher, comentar suas façanhas sexuais, exercitando sua ludicidade no contato com os ideais de disputa, competição e vitória.

Outro ponto digno de nota diz respeito ao fato de que, para os homens jovens, adolescentes, torna-se um complicador, na percepção das trabalhadoras de enfermagem, serem encaminhados para atendimento em uma sala caracterizada como "pediatria", ou em setores reconhecidos como de aten ção às mulheres, como a mastologia. Ou seja, assinalam o não reconhecimento de sua condição diferenciada, seja de gênero, seja de faixa etária, desencadeando reações de vergonha, favorecidas pelo preconceito epela falta de informação: "Eu quero o clínico por que pediatria, eu não sou mais bebê? Eu falei: masnão pode, o clínico nosso aqui só atende pessoa da terceira idade, hipertenso, diabético, você é velhinho? $M$ as eu não quero pediatria não, eu tenho vergonha! Esse Projeto do Homem Jovem eu tento tirar um pouquinho do preconceito, porque eles vêm muito envergonhados." (GF, 1RJ)

Os entrevistados destacam ainda que, no grupo dos homens jovens, as necessidades e as demandas estão associadas ao campo da sexualidade, do controle da concepção e até mesmo do uso da camisinha para prevenção das DST, bem como das alterações de comportamento.

A preferência pela atenção a uma faixa etária maisidosa - a do "vovozinho" - comparececomo uma atitude de proteção, que vincula ao idoso a complacência, paciência e tranquilidade, em um sistema que acaba por exigir dos usuários essas qualidades: "Eu confesso que eu me sinto melhor atendendo vovozinho, porque ele já deixou um pouco a agressividade delado, porqueeu sinto mais segurança emenos problema em lidar com essa faixa de população." (Pompeu, médico, 2RJ) 
Os homens de outras faixas etárias parecem manifestar sentimentos de agressividade, impaciência, nervosismo e pressa quando necessitam esperar ou não conseguem atendimento. Associado a isso, há as exigências do trabalho ea necessidade decumprir os compromissos com o mesmo servem como justificativa para não se cuidar: "Estão sempre com pressa, nervosos, eles que rem ir embora correndo por causa do trabalho. E fora dessehorário não tem aten dimento." (GF, 2RJ)

"Os homens nos agridem verbalmente porque acham que estamos enrolando, não entendem queo médico é que não chegou. Você não vê o homem que está em atividade profissional esperando." (GF, 2RJ)

A sedução da diferença geracional e entre os gêneros demarca para a mulher jovem facilidades no acesso ao serviço. Considerando o acesso difícil para ambos, mulheres e homens, as muIheres de um modo geral levariam vantagem, em função de ser o homem que as recepciona e na relação entre os homens cria-se uma estratificação geracional que positiva os idosos no acesso aos serviços: "A mulher nova já começa vigilante. E quando é [de] meia-idade, isso continua. 0 homem novo passa por preguiçoso, longe do serviço, porquequer [0] dia, tá armando. Q uando na faixa altamente produtiva, os próprios colegas de fila acham que ele devia estar trabalhando." (Pompeu, médico, 2RJ)

$\mathrm{N}$ as entrevistas individuais, aparece ainda a dificuldade dos homens em procurarem o serviço de saúde em função da vergonha, associada a um sinal de fraqueza. Nesse sentido, as diferenças socialmente construídas e compartilhadas entre os gêneros comparecem nos pares de oposição força/fraqueza, em que homens emulheres podem alternar essas posições de acordo com a situação: "O homem éaquela pessoa forte, cheio de força, que nunca sentenada. A mulher queéo sexo frágil, agora aos pou cos que está mudando alguma coisa, tem homens quejá senta, já chega pra vocêe pergunta sobre exame de próstata." (Perpétua, enfermeira, 2RJ)

“H omem não tem que se queixar, é forte, não pode reclamar, não pode chorar. São uns preconceitos atrasados, quando na realidade nós sabemos que homem é muito mais fraco do que a mulher." (Pompeu, médico, 2RJ)

Com relação aos sentimentos de vergonha, aparecem ainda no contexto da prevenção do câncer de próstata, dos exames e da percepção dos homens sobre os mesmos: "D e uma maneira geral, [eles] têm vergonha de dizer que foram procurar ou que foram submetidos, até nem submeti- dos, procurar, rastreamento de patologia prostática." (Pompeu, médico, 2RJ)

As expressões timidez, vergonha de perguntar, reservado, resistente, não se expor são utilizadas como recurso para justificar o comportamento masculino de não estar cuidando da saúde. Apontam tais expressões para uma certa perspectiva de resistência masculina ao autocuidado, inclusive como um sinal de fraqueza, de coisa de mulherzinha: "O homem parece ser mais tímido, [tem] vergonha de falar, de expor as coisas para a gente." (Paola, enfermeira, 1RJ)

"As mulheres são mais frequentes, porque elas se tratam. Vocêmanda a mulher ir no ginecologista, manda a mulher ir no cardi ologista, no neurologista, ela vai. 0 homem não vai." (Percival, mé dico, 1RJ)

Esses comportamentos de maior reserva e/ou timidez acabam por influenciar no manejo da abordagem profissional. Ou seja, conseguir ser melhor sucedido na conquista dos homens para o cuidado à sua saúde significa conseguir dominar um vocabulário, ou um repertório deinteresses, adaptar outras práticas no processo de trabalho em saúde que permitam conquistar o homem para a adesão às práticas de cuidado. Para os adolescentes, éimportante ainda reconhecer 0 valor atribuído ao circuito da sociabilidade, do encontro lúdico, onde relações de trocas, não somente simbólicas, mas também materiais, se façam presentes. Para os homens adultos, o recebimento do remédio em casa funciona como um estímulo de lembrança da consulta e de vinda ao serviço, e mais uma vez é assinalada a importância do circuito de troca, daquilo que $\mathrm{M}$ artins ${ }^{19}$ identifica como "circulação debens de cura". Esses bens de cura seriam referidos como a atenção, a confiança, as palavras técnicas recebidas e os re médios. As redes informais de confiança eamizade geradas no interior dos serviços e fora deles favorecem a adesão ao serviço de saúde ${ }^{21}$.

Nesteeixo, destacaram-sedeforma mais contundente as colocações das trabalhadoras de enfermagem de nível médio participantes dos grupos focais. A facilidade com que evocam os re pertórios pessoais - não somente enquanto profissionais, mas como mulheres comuns - facilita a apreensão dos sentidos associados aos preconceitos, diluídos no senso comum, sem muitas elaborações ou críticas que filtrem aquilo que possa ser pouco considerado no meio técnico. Foi com esse segmento que os temas da diferença entreos gêneros, que privilegia mulheres e crianças, e as críticas a um sistema hierárquico e burocrático presentificam-se. N esse último aspecto, a crítica 
aos privilégios concedidos às categorias de nível superior é interpretada enquanto interferências fortes na organização da atenção ao usuário. A privacidade é referida basicamente como uma prerrogativa de ofertar um melhor cuidado ao usuário.

\section{Considerações finais}

Dentreas conclusões do estudo, destaca-seo fato de os serviços de saúde serem majoritariamente ocupados por profissionais do sexo feminino, 0 que parece dificultar a abordagem de alguns temas, em particular relacionados ao campo da sexualidade, em que a presença de um profissional homem poderia ser um facilitador.

Os dados da pesquisa também revelaram que, para compreender a organização de um serviço prestado a usuários homens, se faz necessário entender tanto a lógica do atendimento a esses usuários, quanto à esfera estrutural em queesses mesmos serviços são oferecidos como um todo. N esse cenário, dois aspectos precisam ser observados. 0 primeiro diz respeito ao fato de que 0 sistema de saúde opera segundo uma estrutura preestabelecida em quea oferta se constrói a partir de um não lugar, ou seja, os homens, de um modo geral, não são usuários da aten ção primária e, sendo assim, o que lhes é oferecido está bom. 0 segundo é construído a partir de uma lógica do senso comum que, por falta de investimento do primeiro, pouco viabiliza a presença mais efetiva dos homens nos serviços de saúde.

Aprofundando a discussão, verifica-se que os depoimentos de alguns profissionais reforçam a percepção de alguns homens de que as unidades básicas de saúde são destinadas apenas para muIheres e crianças'. Isso revela que nem sempre os profissionais de saúde conseguem se descolar do senso comum em que os sujeitos são vistos muito mais pela doença quelhes acometedo quepelo seu gênero. Superar esse lugar comum é de fundamental importância para que se problematizem questões do campo simbólico no sentido de contemplar os temas do universo masculino. Dentre esses temas, destaca-se a dificuldade que homens têm em se desnudar para o profissional em virtude de não terem sido habituados a se expor ao médico, diferentemente da socialização feminina². A não abordagem desse tema pode fazer com que não se reconheça a necessidade deprivacidadedos homens, tão mencionada pelos profissionais. Considerar essas eoutras questões pode vir a contribuir para que os serviços também se tornem um espaço para os homens numa perspectiva relacional de gênero. $E$, por consequência, desconstruir a invisibilidade dos homens nos programas de saúde de atenção primária que pode afastá-los da condição de cuidadores de si e dos outros.

\section{Colaboradores}

R Gomes, M CN M oreira, EF Nascimento eLEFS Rebello participaram igualmente detodas as etapas da elaboração do artigo, enquanto MTC Falcão e LB Schraiber participaram da elaboração e redação final do texto. 


\section{Referências}

1. Gomes R, Nascimento EF. A produção do conhecimento da saúde pública sobre a relação homemsaúde: uma revisão bibliográfica. Cad Saude Publica 2006; 22 (Supl 5):901-911.

2. Gomes R, Nascimento EF, Araújo FC. Por que os homens buscam menos os serviços de saúde do que as mulheres? As explicações de homens com baixa escolaridade e homens com ensino superior. Cad Saude Publica 2007; 23(3):565-574.

3. Gomes R, Rebello LEFS, Araújo FC. A prevenção do câncer de próstata: uma revisão da literatura. Cien Saude Colet 2008; 13(1):235-246.

4. Schraiber LB, Gomes R, Couto MT. Homens na pauta da saúde coletiva. Cien Saude Colet 2005; 10(1):7-17.

5. Gomes R. Sexualidade masculina, gênero e saúde. Rio de Janeiro: Fiocruz; 2008.

6. Costa RG. Saúde e masculinidade: reflexões de uma perspectiva de gênero. Rev. bras. estud. popul. 2003; 20(1):79-92.

7. Couternay WH. Constructions of masculinity and their influence on men's well-being: a theory of gender and health. Soc Sci M ed 2000; 50:1385- 1401.

8. Korin D. Nuevas perspectivas de género en salud. Adolescência Latinoamericana 2001; 2(2):67-79.

9. Schraiber LB. Equidade de gênero e saúde: o cotidiano das práticas no Programa Saúde da Família do Recife. In: Villela W, Monteiro S, organizadores. Gênero e saúde: Programa Saúde da Família em questão. Rio de Janeiro: Abrasco/Brasília: Fundo de População das Nações U nidas; 2005. p. 39-61.

10. Gomes R. Sexualidade masculina e saúde do homem: proposta para uma discussão. Cien Saude Colet 2003; 8(3):825-829.

11. Gastaldo EL. A forja do homem de ferro: a corporalidade nos esportes de combate. In: Leal OF, organizadora. Corpo e Significado: ensaios de antropologia social. Porto Alegre: Editora da Universidade/ UFRGS; 1995. p. 207-226.

12. Keijer B. Hasta donde el cuerpo aguante: género, cuerpo e salud masculina. In: Cáceres $C$, Cueto $M$ Ramos M, Vallenas SM, compiladores. La salud como derecho ciudadano: perspectivas y propuestas desde América Latina. Lima: Universidad Peruana Cayetano Heredia; 2003. p. 137- 52.

13. Nemes Filho A. A U nidade Básica e o Sistema de Saúde. In: Schraiber LB, Nemes MIB, M endes-Gonçalves RB, organizadores. Saúde do Adulto: programas e ações em unidade básica. 2aㅡ ed. São Paulo: Hucitec; 2000. p. 276-286.
14. Andrade LOM, Barreto ICHC, Bezerra RC. Atenção primária a saúde e estratégia saúde da família In: Campos GWS, M inayo M CS, Akerman M, Drumond Junior M, Carvalho Y, organizadores. Tratado de Saúde Coletiva. São Paulo: Hucitec/Fiocruz; 2008 . p. $783-836$.

15. M endes-Gonçalves RB. Tecnologia e organização das práticas de saúde: Características tecnológicas do processo de trabalho na rede estadual de Centros de Saúde de São Paulo. São Paulo: Hucitec/Abrasco; 1994.

16. Bourdieu P. 0 poder simbólico. Rio de Janeiro: Bertrand Brasil; 1989.

17. Gomes R, Souza ER, M inayo MCS, Silva CFR. Organização, processamento, análise e interpretação de dados: o desafio da triangulação. In: M inayo MCS, Assis SG, Souza ER, organizadores. Avaliação por triangulação de métodos: abordagem de programas sociais. Rio de Janeiro: Fiocruz; 2005. p. 185-221.

18. Gomes R. Análise e interpretação de dados de pesquisa qualitativa. In: M inayo MCS, organizadora. Pesquisa social: teoria, método e criatividade. Petrópolis: Vozes; 2007. p. 79-108

19. Martins PH. Contra a desumanização da medicina: crítica sociológica das práticas médicas modernas. $\mathrm{Pe}$ trópolis: Vozes; 2003.

20. Costa E. A confraria da esquina. $O$ que os homens de verdade falam em torno de uma carne queimando: etnografia de um churrasco de esquina no subúrbio carioca. Cien Saude Colet 2005; 10(1):262-263.

21. M oreira MCN. Dádiva e rede na saúde: circuitos de troca e construção de estratégias de cuidado. In: Pinheiro R, Mattos RA, organizadores. Razões públicas para a integralidade em saúde: 0 cuidado como valor. Rio de Janeiro: IM S-UERJ/CEPESC/Abrasco; 2007. p. 301-316.

Artigo apresentado em 25/08/2008

Aprovado em 14/01/2009

Versão final apresentada em 14/02/2009 